\title{
DENTOSTOMINA BESNARDII, NOVA ESPÉCIE DE FORAMINIFERO
}

(Recebido em 5/12/1960)

Walter Narchi *

Carman, em 1933, estudando foraminiferos recentes de águas rasas das Bermudas, descreveu um novo gênero pertencente à família Miliolidae.

A distinção genérica é feita pela abertura, cuja superfície interna apresenta projeções espaçadas, separadas por depressões, tendo um longo dente bífido.

Nenhuma citação bibliográfica foi feita com referência ao gênero em águas brasileiras; encontrei-o no material confiado a mim pelo primeiro Diretor do Instituto Oceanográfico da Universidade de São Paulo, Prof. Wladimir Besnard. Poucas espécies são conhecidas nêste gênero e possivelmente pertencem a êle espécies como Quinqueloculina.

\section{Fam. Miliolidae}

Gên. Dentostomina Carman, 1933

Dentostomina besnardii sp. $\mathrm{n}$.

(Figs. 1-6)

Carapaça forte, oval, comprimida lateralmente. Cinco câmaras de periferia angulada, visíveis externamente. Suturas profundas mascaradas pelo grande acúmulo de grãos de quartzo e de outros minerais que revestem a carapaça. Abertura circular, com dentículos internos. Dente bífido bem desenvolvido cuja bifurcação está voltada para a última câmara.

A espécie é próxima a D. guraboensis Bermudez, 1949, distinguindo-se desta pela posição do dente bífido prêso na penúltima câmara e cuja bifurcação se dirige para a última, por ser mais alongada e

* Departamento de Zoologia da Faculdade de Filosofia, Ciências e Letras da Universidade de São Paulo. 
também pelo tamanho dos grãos que compõem a testa. Esta espécie é proveniente de uma formação do Mioceno e a posição do dente pode ter sido produto de mutação.

Holótipo da espécie dedicada à memória de Wladimir Besnard, encontra-se na Coleção de foraminíferos da Divisão de Oceanografia Biológica do Instituto Oceanográfico, sob n. ${ }^{\circ} 17 / 1$.

Comprimento $-2 \mathrm{~mm}$; largura $1,3 \mathrm{~mm}$.

OCORRÊNCIA - Vários exemplares foram encontrados: 9 no Banco de São Tomé (Lat. $22^{\circ} 08^{\prime} \mathrm{S}$ - Long. $40^{\circ} 39^{\prime} \mathrm{W}$ ) e um em Trindade (Lat. $20^{\circ} 33^{\prime} \mathrm{S}$ - Long. $29^{\circ} 22^{\prime} \mathrm{W}$ ). Mostram algumas diferenças na conformação da bôca, no tamanho, e na presença dos dentinhos da abertura, mas continuam dentro da variação específica.

O holótipo procede do Banco de São Tomé, a uma profundidade de 39 metros.

\section{S U M M A R Y}

A description is given of Dentostomina besnardii, new species, from Banco de São Tomé (Lat. $22^{\circ} 08^{\prime} \mathrm{S}$ - Long $40^{\circ} 39^{\prime} \mathrm{W}$ ) and Trindade (Lat. $20^{\circ} 33^{\prime} \mathrm{S}-$ Long. $29^{\circ} 22^{\prime} \mathrm{W}$ ), coast of Brazil.

The species is similar to D. guraboensis Bermudez, 1949, differing from it by the position of the bifid tooth and the size of the grains which form the test.

\section{B I B L I O G R A F I A}

Carman, K. W.

1933. Dentostomina, a new genus of the Miliolidae. Contr. Cush. Lab. Foram. Research, vol. 9, part 2, p.31-32, fig. 6 a-c.

Bermudez, P. J.

1949. Tertiary smaller Foraminifera of the Dominican Republic. Cush. Lab. Foram. Research, Sp. Publ. n. ${ }^{2}$, p. IV +322 , pls. $1-26$.

\section{ESTAMPA I}

Figs. 1-3 - Tipos de aberturas encontradas em 3 exemplares; Fig. 1 com o dente bífido quebrado.

Fig. 4 - Dentostomina besnardii, vista frontal.

Fig. 5 - Dentostomina besnardii, vista dorsal.

Fig. 6 - Dentostomina besnardii, vista da abertura. 


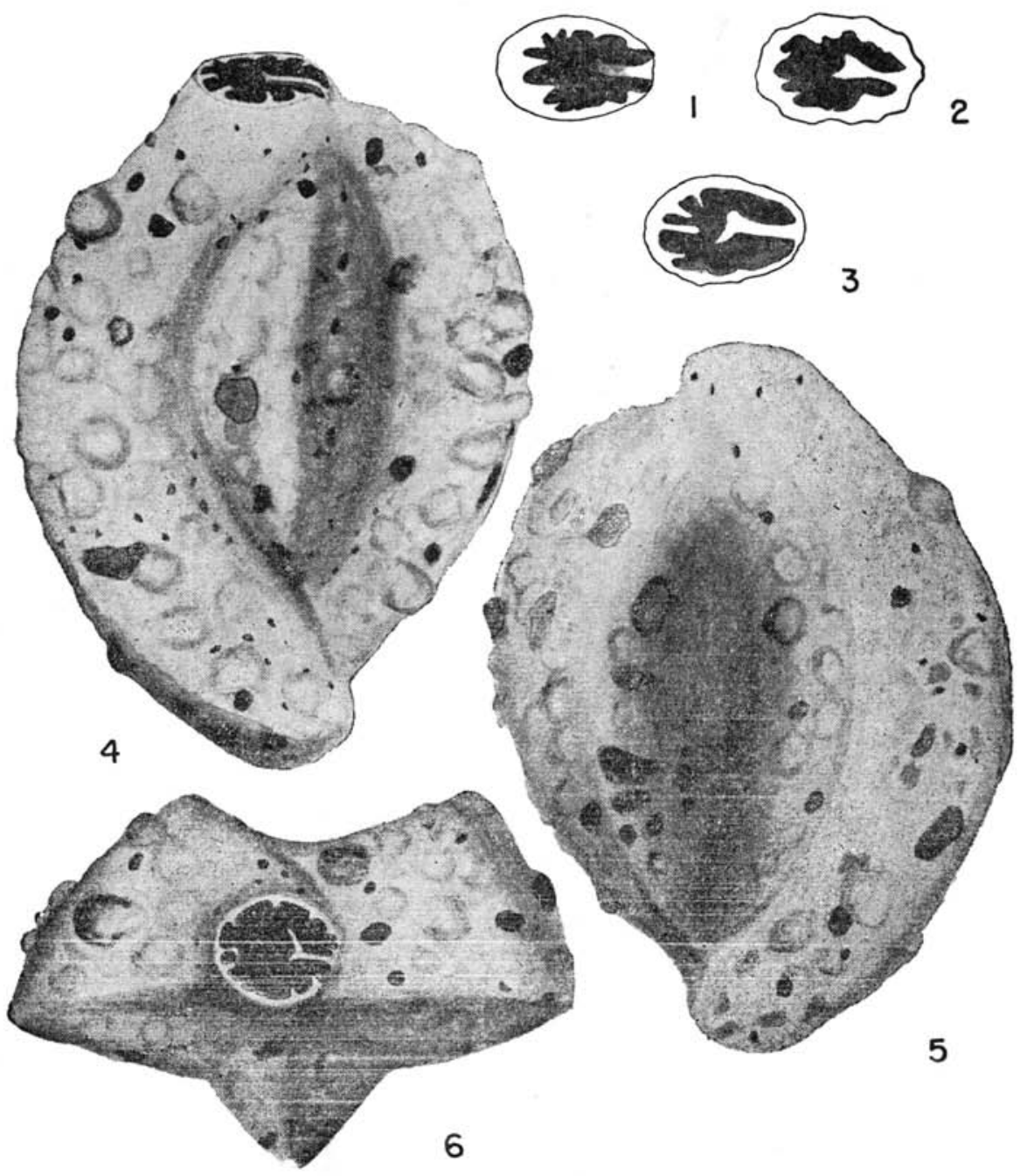

